\title{
DESPERTAR AROCHENO Y AROCHENISMO, MOVILIZACIÓN POLÍTICA EN UN ENTORNO RURAL DE SIERRA http://dx.doi.org/10.33776/hh.v15i0.5290
}

Elena GonzÁlez García UNIVERSIDAD DE SEVILLA elenagongarc@gmail.com

Fecha de recepción: 23/09/2019

Fecha de aceptación: 9/10/2019

\section{Resumen}

El despertar arocheno fue un periódico local del municipio de Aroche (Huelva) que salió a la luz en 1930 en un contexto de agitación política municipal. Aunque tuvo una vida breve intentó ser abanderado del "arochenismo" y efectuar una defensa de los intereses municipales por encima de facciones. A través de esta publicación y los acontecimientos locales trabajados en el archivo histórico municipal hemos podido conocer la movilización y desmovilización de los munícipes y ver las expresiones de la cultura política de este municipio.

\section{Palabras Clave}

Movilización política; cultura política; arochenismo; rural; municipal.

\section{Abstract}

The local newspaper "Despertar Arocheno" appeared in 1930 when a political commotion context was taking place in Aroche (Huelva). This newspaper was short-lived nevertheless tried to defend the "arochenismo" and support the local interest beyond personal interest. The "Despertar Arocheno" and local facts provided by the local historical archive, one as much as the other, has offered us knowledge about the local political movilization and the political culture of Aroche.

\section{KEY WORDS}

Political movilization; political culture; arochenismo; rural; municipal.

"Despertar Arocheno y arochenismo. Rural political movilization".

Aunque el mundo rural no ha gozado de protagonismo en lo que a movilización política se refiere, contamos con varios trabajos de referencia que han cuestionado la incapacidad del medio rural andaluz para participar en procesos políticos de cons- 
trucción de la democracia y la ciudadanía ${ }^{1}$. A este respecto, Herrera, Markoff y Villa ${ }^{2}$ han señalado la necesidad de descender al ámbito local para analizar las interacciones complejas del proceso de construcción democrática, y ver si el mundo rural, excluido tradicionalmente de los relatos sobre la historia de la democracia, tuvo un papel importante.

En el ámbito municipal los republicanos financiaron y fundaron numerosos periódicos y revistas que se convirtieron en altavoces de sus programas y en medios para la denuncia de la mala administración municipal. Según Santiago Jaén ${ }^{3}$ los republicanos organizaron además numerosos actos políticos: mítines y manifestaciones, que dieron visibilidad a las clases populares y trabajadoras que por primera vez durante el sexenio ocuparon el espacio público. Jordi Pomés ${ }^{4}$ ha destacado la importante relación habida entre republicanismo y mundo rural, donde se dieron unos lazos de unión más estrechos y durante mayor tiempo que en el mundo urbano. Hecha esta introducción pasamos a situarnos en nuestro escenario de referencia.

De acuerdo a De Lara, Domínguez y Peña ${ }^{5}$ las masas rurales onubenses carecían de toda movilización política y parecían ganadas casi absolutamente por un férreo caciquismo conservador, con la consecuente debilidad de la organización sindical agraria. No obstante, no creemos que sea ésta una realidad homogénea y para ello a lo largo de este trabajo describiremos la movilización política que se gestó y desarrolló en un municipio de sierra como es Aroche.

\section{CONTEXTO DE CRISIS AGRARIA Y DISTRIBUCIÓN DESIGUAL DE LA PROPIEDAD}

Si hay algo que no cambió con la llegada del siglo XX en la comarca sierra fueron las crisis agrarias y de subsistencia. Alcaldes de municipios como Aroche y Santa Olalla comunicaban en la prensa en 1905 noticias pesimistas respecto al problema agrario en dichos pueblos ${ }^{6}$. Según el relato autobiográfico de Félix Lunar $^{7}$ el sueldo medio de un jornalero arocheno en 1900 era de unos dos reales y medio, no llegaba a la peseta, el de los mineros alcanzaba las 2 pesetas. El sueldo además siempre estaba dispuesto a modificaciones según pareceres de los caciques. Según Núñez Lasso de la Vega ${ }^{8}$ estos

1 Manuel GONZÁLEZ DE MOLINA, et al.: Historia, identidad y construcción de la ciudadanía. Por una relectura de la historia contemporánea de Andalucía. Sevilla: Centro de Estudios Andaluces, 2005.

F. ACOSTA RAMÍREZ y Salvador CRUZ ARTACHO: Democracia y mundo rural en Andalucía, 18901936: propuestas para la revisión crítica de algunos tópicos historiográficos. X Congreso de la Asociación de Historia Contemporánea. Nuevos horizontes del pasado: culturas políticas, identidades y formas de representación. Universidad de Cantabria. 2010. A, HERRERA, M. GONZÁLEZ DE MOLINA, y J. MARKOFF: "Democracia y mundo rural en España". Ayer, 89 (2013).

2 A, HERRERA, J. MARKOFF, J. y VILLA, I. "La democratización del mundo rural en Espańa en los albores del siglo XX. Una historia poco conocida”, Ayer, 89 (2013), pp. 21-42.

3 S, JAÉN: "El difícil camino de la democracia en una provincia agraria: Jaén, 1868-1910" XV Congreso Historia Agraria de la SEHA (2016), https://lisbon2016rh.files.wordpress.com/2015/12/0020-onw1.pdf

4 J, POMÉS “Sindicalismo rural republicano en la España de la Restauración”. Ayer, 39 (2000), pp.103-133.

5 J.C. DE LARA; R.M. DOMÍNGUEZ; M.A PENAA, "Huelva y la crisis de 1917”. Huelva en su Historia, 3, (1990).

6 s.a. "La Época" 16 de septiembre de 1905.

7 Félix, LUNAR: A Cielo Abierto. De Rio Tinto a Norteamérica. Ed. Consulcom. Huelva. 2011.

8 J.M. NÚNEZZ LASSO DE LA VEGA: "La industria del corcho", XIII Jornadas del Patrimonio de la 
bajos sueldos en relación con los metalúrgicos no produjeron movimientos campesinos ni durante la huelga de 1917 en la comarca sierra. Sin embargo en algunos ejemplares de la prensa nacional en 1918 aparecen noticias de amotinamientos ocurridos en Aroche debido a la precaria situación que vivían los vecinos. En el periódico "La época" se dice que el vecindario del pueblo de Aroche se amotinó por la carestía de subsistencias y asaltó algunos establecimientos. Y en el periódico "La Nación” se dice que se había declarado una huelga general de mineros por haberse subido el precio del pan y la guardia civil estaba patrullando las calles?.

Junto a la crisis agraria permanecía el mal endémico de esta comarca: el reparto desigual de la tierra, en la gran mayoría de las ocasiones en manos de personas ajenas al municipio. Según el amillaramiento de riqueza rústica de 1912 para Aroche aun siendo los arochenos mayor número de propietarios de la tierra, 65\% frente al $35 \%$, son los hacendados los propietarios de las explotaciones de más extensión. Si analizamos los datos por hectáreas encontramos una preeminencia de los vecinos en las explotaciones de menor extensión, de las 273 explotaciones de menos de 5 has, 216 pertenecen a vecinos y solo 57 a hacendados. Estas explotaciones suponen sólo un $2,4 \%$ del total de las hectáreas amillaradas. De todas las hectáreas amillaradas del municipio, el 63,23\% de las mismas pertenecen a personas ajenas al municipio de Aroche $^{10}$.

Según el censo electoral de 1923 en Aroche la propiedad aparece concentrada en pocas manos ( $4 \%$ ), hay un $5 \%$ de habitantes que son calificados como labradores que poseen medios de producción (como por ejemplo animales de tiro), pero que deben arrendar las tierras. Los jornaleros siguen siendo la inmensa mayoría, un $74 \%$ de la población activa. El sector artesanal se acerca al $6 \%$, mientras que el industrial contando los molineros llegaba al $3 \%$ del total. Los comerciantes alcanzaban el $1 \%$. Todas estas cifras dan como resultado grandes niveles de paro y un mercado de trabajo fuertemente dependiente de los medianos y grandes propietarios de tierras. La pobreza, por tanto, es una constante en la mayoría de las familias arochenas (Sancha F. 2004 y Fernández González, J. 1999).

\section{El NACimiento de la SOCIEDAd DE ObReros "El Alba”}

En torno a 1902 según descripción autobiográfica de Félix Lunar fechamos el nacimiento de la sociedad de obreros "El Alba", su origen es una cuadrilla de trabajadores del Álamo ${ }^{11}$ : "dieciocho montaraces y un corchotaponero", al poco tiempo llegaron a ser 800 personas. Lunar compartía sus actividades entre el Centro Obrero y el Republicano.

\footnotetext{
Comarca de la Sierra. (Huelva) Diputación Provincial de Huelva , Cortelazor la Real , 295-313.1999.

9 s.a. "La época" lunes 4 de febrero de 1918.

Martí NÚNEZZ: La Nación. 6 frebrero de 1918.

10 Amillaramiento de riqueza rústica 1912. “ Repartimiento y Amillaramientos de Riqueza Rústica 19031915”. Legajo 915. Archivo Municipal de Aroche.

11 En torno a 1900 el padre de Félix Lúnar fue contratado como guarda en la finca de "El Álamo", propiedad de Carmen Sánchez Arjona y Boza, Condesa del Álamo.
} 
En 1903 había tenido lugar la constitución del comité del partido republicano en Aroche $^{12}$ que tenía como presidente efectivo a Miguel Lobo Carquesa. Aroche a través de representación asistió al Congreso Internacional de Librepensadores de Roma en septiembre de 1904.

Félix Lunar conoce a través de Miguel Lobo presidente del partido republicano arocheno a Francisco Liñán, médico y presidente del partido republicano corteganés y a José Morita, destacado elemento del republicanismo. Fraguada la relación con ambos los invitó a dar un mitin en Aroche, el cual terminó disuelto por la guardia civil a orden de la alcaldía ${ }^{13}$. Aun así la actividad política no quedó inmovilizada. Según Lunar existía un casino republicano donde se podía leer prensa y discutir sobre estas ideas republicanas; Lunar y otros compańeros mostraron también un marcado carácter anticlerical. En 1908 Félix Lunar firmando como "el ateo Chico" escribe en las Dominicales de Libre Pensamiento "Matando el cuerpo por salvar el alma" donde hace una crítica frontal a la religión, a los sacerdotes y a la marginación a la que fue sometido en Aroche por discurrirse en parámetros lejos de la religión abogando por el librepensamiento ${ }^{14}$.

A principios de siglo encontramos una intensa actividad política municipal, en 1904 apareció un artículo en las dominicales de libre pensamiento ${ }^{15}$ en el que R. de Castilla Moreno hace una crítica a una parte de la sociedad arochena. El autor reprende no sólo a los acomodados y socios del casino "La Amistad", también a aquellos que se reunían en el centro de Unión Republicana al objeto de tomar café y pasar la vista a la prensa periódica. El autor reprocha ambas actitudes por mostrarse ajenas a las condiciones de vida miserables de ciertos vecinos de Aroche de los que sólo los que llama "hijos del trabajo" son conscientes. Se refería a los miembros de la Sociedad "El Alba", éstos según describe el artículo "se dirigían al domicilio de 3 viudas pobres a entregarles el socorro de 75 ptas que habían conseguido reunir “ ¡Rasgo hermoso de altruismo y timbre de inmarcesible gloria para la floreciente Sociedad "El Alba!".

Sobre la Sociedad "El Alba" sólo se tiene un reglamento de 1921. Los fines primordiales de la misma serían proporcionar un centro de reunión y un foro de debate donde los obreros de Aroche pudieran culturizarse sindicalmente ${ }^{16}$. Lunar y la sociedad emprendieron acciones en pos de la defensa de los trabajadores, entre ellas se buscó a varias personas de edad avanzada y experiencia para que hicieran una tarifa de salarios por trabajo. Acordaron con el Ayuntamiento la organización del reparto del trabajo y se eliminó la costumbre caciquil de acudir a buscar a los obreros a la plaza del pueblo cada mañana. Ahora se priorizaba a los padres de familia con cargas familiares y estos trabajadores tenían que ser aceptados por los patronos. La patronal reaccionó organizándose en Socie-

12 s.a. "Las Dominicales de Libre Pensamiento."29 de mayo de 1903.

13 Félix LUNAR: A cielo abierto...,p. 131

14 Félix Lunar. "Las Dominicales de Libre Pensamiento" 27 de noviembre de 1908.

15 R. de Castilla Moreno: "Un Contraste”. Dominicales de librepensamiento. 9 de septiembre de 1904.

16 Antonio MÚNIIZ CARRASCO, Jesús BERROCAL MONTERO Y Nieves MEDINA ROSALES (2007) La historia silenciada. Las víctimas arochenas de la represión franquista. 2º Edición ampliada y revisada. Ed. Ayuntamiento de ARoche. Gráficas Aroche. 
dades de Propietarios Agrícolas y Ganaderos y luchando por el poder local. La Sociedad hubo de reaccionar en ocasiones como en el tiempo de la siega, única temporada del año en que los trabajadores tienen alguna oportunidad de ahorrar algún dinero. Según la descripción autobiográfica de Lunar la primera semana que se generalizó el trabajo, "quedaron sin trabajo 18 hombres, todos los de la junta directiva de la Sociedad"17. La Sociedad se organizó para que si a algunos se les marginaba no trabajara nadie y prepararon el terreno para que Antonio Pérez Macías, un joven de ideas progresistas, fuera alcalde.

En 1919 se constituye el Partido Socialista Obrero Español junto a la Agrupación Local de la UGT a la sombra de Antonio Domínguez Mozo “Antońino”. Antonio Domínguez aparece ligado a la Sociedad convirtiéndose en su secretario en $1921^{18}$.

En febrero de 1924 el Partido Socialista arocheno plantea una serie de exigencias al gobierno civil, e impone a un alcalde, el socialista Méndez Castilla como condición para su colaboración en la gestión municipal. La preponderancia de los socialistas en la dictadura se traduce en fricciones con el poder de los patronos encarnado desde 1926 en la figura del alcalde José Campos Rodríguez. El centro indiscutible de la actividad política del momento es el proyecto de la comunal, un proyecto industrial que incluía entre otras actividades una fábrica de harinas, generada a partir de los beneficios del bien comunal "La Dehesa de la Contienda"19.

\section{La Comunal}

La idea de la comunal tenía su origen en el desigual reparto de la propiedad de la tierra y el importante movimiento jornalero que se había desarrollado desde finales del siglo XIX. La impulsora de "La Comunal" fue la Asociación de Obreros El Alba. El 28 de febrero de 1921 esta agrupación había propuesto al ayuntamiento la creación «de una fábrica de electricidad que con el tiempo se transformara en harinera" ${ }^{20}$.

El origen de la fábrica será el pleno municipal del ayuntamiento de Aroche de 10 de mayo de 1921 que decide acabar con el reparto de los fondos en metálico generados como beneficio de la explotación de la finca "Dehesa de la Contienda". Los organismos que controlaron la fábrica fueron la Junta de Contiendas y el Sindicato Agrícola de Aroche. Los choques entre la Junta y el Ayuntamiento van a ser frecuentes habida cuenta de la diferencia de intereses que existe entre ambos organismos. ${ }^{21}$.

En 1926 en el mes de septiembre un acuerdo de la Junta Administrativa de la fábrica de harinas tuvo como consecuencia un sonoro pleito con el Ayuntamiento de Aroche.

17 Félix LUNAR: A cielo abierto...,p. 147 "La Sociedad hemos de defenderla a todo trance. Y al primero que falta a su deber para con ella, le haremos la vida imposible en este pueblo" p. 173.

18 En mayo de 1923 nacía el periódico izquierdista "La Coalición” con intención revolucionaria, su director: Francisco Méndez Castilla, en su editorial dice: "éste es un periódico fundado por los conservadores, por sus atropellos que obligan a defenderse. Los caciques, ejemplares existen aquí los hay en todos los pueblos, es necesario extirparlos (Múñiz et al.: La historia...) y Félix, SANCHA: "Moler, ver y comer. El movimiento obrero en la sierra de aroche (1920-1930)". XVIII Jornadas del Patrimonio de la Comarca de la Sierra. Rosal de la Frontera (Huelva), Diputación Provincial, Rosal de la Frontera, 59-91. (2004).

19 Ibid

20 Félix Sancha: Moler, ver y comer...

21 Félix Sancha: Moler, ver y comer... 
Había un amplio sector de la sociedad arochena que deseaba que La Comunal perdiera la tutela del Ayuntamiento, sus defensores empiezan a gestar lo que después será el Sindicato Agrícola de Aroche formado por todos los vecinos, el cual finalmente se hará con la propiedad y control de la fábrica. El 30 de marzo de 1928 se aprueba el Reglamento del Sindicato Agrícola de Aroche y en marzo de 1929 se retoma un viejo proyecto para la implantación de una empresa productora de electricidad. El 3 de julio de 1929 el Ayuntamiento acuerda por unanimidad hacer cesión de la fábrica de harinas y sus terrenos al Sindicato Agrícola ${ }^{22}$.

Durante todo el año de 1930 se produce una intensa actividad política local como consecuencia de la decadencia de la dictadura de Primo de Rivera y la efervescencia republicana. Esta actividad se manifiesta en la aparición de tres periódicos: "El fraternal" y "El Despertar Arocheno", ambos de tendencia socialista; y el "Nosotros", de tendencia conservadora $^{23}$.

\section{La aparición de El Despertar Arocheno}

En 1930 hace aparición el periódico local "El Despertar Arocheno" el cual se definía como "defensor de los intereses morales y materiales de la villa y de la comarca serrana". En la publicación se hace referencia al "arochenismo" y a la necesidad de una defensa compartida por todos de los intereses comunes y de un espíritu colectivo de mejoramiento. En uno de los primeros números un artículo titulado "Nuestra Comarca" ${ }^{24}$ de José Andrés Vázquez, se apela a la necesidad de un sentimiento parecido a nivel comarcal pues dice "el orgullo de ser serranos carece de uno de los mayores defectos: es un sentimiento individual sin la menor trabazón colectiva y por tanto sin ningún poder eficaz".

"El despertar arocheno" fue utilizado por muchos como expositor desde el que hacer crítica. El clima social y político en estos años debió cambiar, uno de sus primeros editoriales titulado "Siguiendo" ${ }^{25}$ denunciaba el inmovilismo de los vecinos ante la ineficacia de la gestión municipal. Socialistas como Manuel Sancha y Antonio Domínguez Mozo eran frecuentes participantes en el periódico, éste último llegó a ser director del mismo. En el despertar arocheno se hacen públicas las reuniones del Sindicato Agrícola creado a partir de la sociedad "El Alba". Las sesiones del sindicato y la gestión de "La comunal" y la Contienda se publican en el periódico local pues son de incumbencia de la totalidad del municipio ya que todos los vecinos son propietarios de los bienes comunales y miembros del Sindicato Agrícola.

El dirigente socialista municipal Manuel Sancha, se convirtió en adalid de la crítica al caciquismo y así lo mostró en el periódico local. Para Sancha la política de esta forma es el medio de que se valen los caciques para persecuciones de hombres que tienen ideas y critican malos actos políticos y administrativos. La política debía estar según él:

23 Múñiz et al.: La historia...

24 José Andrés VÁZQUEZ. "Nuestra Comarca”. Despertar Arocheno no 6. 3 de Julio de 1930.

25 S.a. "Siguiendo". Despertar Arocheno. no 4.1 de junio de 1930. 


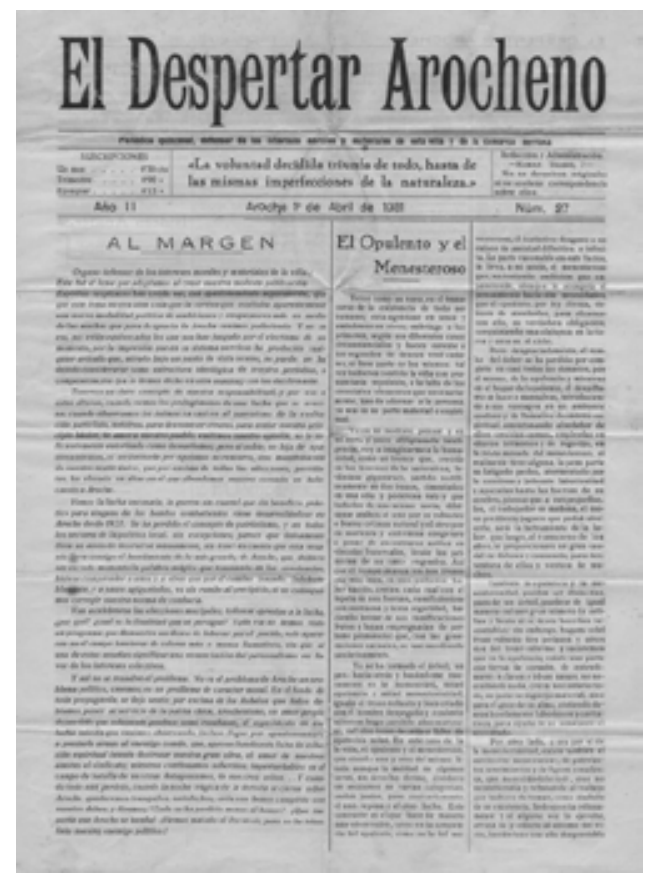

"para hacer las leyes que nos pongan a todo ciudadano en iguales condiciones en los derechos de propiedad, en tanto estos existan, en los derechos sociales, en amparo al desvalido, al demente, al huérfano, que castigan al criminal, al malhechor, prohíba tanto privilegio, en contra de tanta miseria"... "sin política gobiernan las dictaduras para desgracia de los ciudadanos de aquel suelo que las padece". "Política hay en el adoquinado de una calle"... "todo es política y nada se hace sin ella"26.

El editorial del siguiente número del periódico se titulaba "Reiterando" ${ }^{27}$, en línea con la crítica y la denuncia al mal gobierno se solicitaba el ejercicio fiscalizador del gobierno municipal:

“¿Por qué no hace una serena y recta investigación de cuanto atañe a chanchullos administrativos?"... "no somos rencorosos; si exigentes, para ver de crear un nuevo estado de cosas"... "céntimo de pobre comido, responsabilidad que acatan los abúlicos en ejercicios directivos". En este editorial se exigen una clarificación de las cuentas municipales y sacar a luz pública actos delictivos exigiendo su reparación.

Se hace en el periódico una defensa de la participación en política. P. Gando ${ }^{28}$ en un artículo titulado "apoliticismo, no" incita a no declararse apolítico en un momento político de gran trascendencia:

26 Manuel SANCHA. “Adelante si, pero,,”. Despertar Arocheno. no 4.1 de junio de 1930.

27 Editorial "Reiterando". Despertar Arocheno. No5. 15 Junio de 1930.

28 P. GANDO. “Apoliticismo no”. Despertar Arocheno. No7. 13 Julio de 1930. 
"el actual momento político en España, es de un interés insospechado y de una ingente trascendencia, porque se ventila la forma de gobierno que ha de regir nuestros destinos en lo futuro después de un caos político de medio siglo, teniendo por colofón una procelosa dictadura”.

En relación a la denuncia del caciquismo e inmovilismo hemos encontrado una "crónica" realizada por Pedro Maestre en $1930^{29}$ en la que distinguía entre "Los caballeros de la tierra y los enemigos del sol, dos clasificaciones de la historia del pueblo". A los primeros los definía como:

"los verdaderos legionarios de la tierra a la que dedicaban por entero su vida. A cualquiera de aquellos señores, austeros, que practicaban sin conocerlo el imperativo categórico de la moral a quien hubieran preguntado qué cosa era la causa pública, salvo raras excepciones, no hubiese sabido responder"...” sin más fe que la del propio esfuerzo vivieron de espaldas a cuanto significare acción social.

El autor decía que un pueblo como Aroche, "con un patrimonio comunal de varios millones, tenía derecho a otras orientaciones". Los enemigos del Sol, eran la docena de intelectuales desocupados en su mayoría que suele haber en cada pueblo, que se dedicaban a discutir sobre política.

"Mientras esto ocurría; mientras los unos trabajaban confiados en la buena fé y los otros discutían, dos hombres audaces, en turno normal y en franca hostilidad, el que mandaba contra el que había cesado, harían "mangas y capirotes" del presupuesto municipal”.

Esta crónica hace una crítica en esencia al imaginario social local, que abandonaba al desamparo su patrimonio y la "res pública", que vivía de espaldas a lo público y lo compartido. Este asunto es recurrente y esta idea ha sido compartida y expresada anteriormente por otros arochenos,

En otros artículos también se haría un llamamiento a despertar conciencias, tal es el caso de "Aroche Progresivo. Para varios jóvenes"30. En este artículo se alienta a los jóvenes arochenos a dejar de ser inactivos ante el caciquismo. El autor dice que el cacique no es el único culpable sino el obrero que conoce los medios y consiente la situación.

"Bien, jóvenes Arochenos, si todos los jóvenes españoles fuesen como vosotros, España continuarían aún aletargada. Mi único comentario a vuestra acción es teneros lástima, pues nada menos que eso merece el que por vanidad se presta a servir de instrumentos a la voluntad del cacique que os dirige para saciar sus apetencias de mando o de otra cosa"... "triunfó la candidatura monárquica en Aroche pero como siempre este triunfo fue logrado embriagando a los inocentes, o lo que es peor, ahogando con vino la Libertad y los pensamientos de esos seres desgraciados".

En relación a las oportunidades que ofrecía este momento de efervescencia política otro artículo titulado "!Aroche... diez minutos"31 mencionaba las posibilidades que

29 Pedro MAESTRE. “Crónica”. Despertar Arocheno. No10 13 agosto de 1930.

30 José BALTASAR Maestre. "Aroche progresivo. Para varios jóvenes”. Despertar Arocheno. 15 de mayo de 1931. No 29.

31 Pedro MAESTRE. “Crónica”. Despertar Arocheno. No5. 15 de junio de 1930. 
se abrían con el periódico local como herramienta con solvencia moral para borrar la desconfianza hacia los cargos públicos por la mala administración y su capacidad para regenerar y hacer progresar al pueblo:

"Sólo un periódico bien orientado, puede convencer al vecindario cuando la entidad lo valga, de que un dividendo mezquino es el chocolate del lobo que no puede redimir de momento su pobreza y en cambio aplicado en su totalidad al fomento de las obras que entrañan el programa cumbre de las aspiraciones de Aroche dará ocasión a que no falte el trabajo y a que nos vayamos acercando poco a poco a la meta que no debe ser otra que el rescate total en cuanto sea posible de esa propiedad rústica actualmente de hacendados forasteros a donde va a parar el esfuerzo de los hijos del pueblo”.

Como podemos advertir algunos de los munícipes no eran impasibles a la situación de concentración de la propiedad en manos de personas ajenas al municipio. Situación que provocaba que la mayoría de los vecinos trabajara como braceros. La concentración de la tierra provocaba un desempleo endémico en este municipio, cuando finalizaban tareas como la siembra, la siega y otras que necesitaban de mucha mano de obra. En Aroche en el expediente que solicitaba la aplicación de la Reforma Agraria en 1932 en este término se nombran una serie de tierras que se dice en tiempo fueron bienes comunales y de propios $^{32}$. En el citado informe se dice que estas fincas indicadas eran susceptibles de expropiación y que en Aroche existía "el predominante régimen de grandes latifundios con lógica consecuencia de carencia de trabajo por obligado paro forzoso". Se acusa aquí a la desigual distribución de la tierra como causante del paro forzoso y estructural que sufría el municipio ${ }^{33}$.

Otro tipo de contribuciones que aparecen en el periódico de tipo reivindicativo tienen que ver con expresiones feministas. Este es el caso del artículo escrito por Carolina Díaz "Y la rubia no quería" ${ }^{4}$ contestando a Paco Carolino quien había escrito un artículo anterior criticando a las mujeres del pueblo por su deshonestidad provocada por las ropas que vestían. Dice la autora que no es culpa de las mujeres que:

"esté tan apegado a sus rancias costumbres que haga consistir la virtud y moralidad de la mujer en tan pequeños detalles como suponen el que la falda esté más o menos corta o el escote más o menos pronunciado?”..."la mujer moderna es tan virtuosa y decente como las de su tiempo de usted o sea la del culo contento, el polisón y otras elegancias por el estilo". Y ustedes queridas compañeras aplacad la indignación”..."seamos indulgentes y copiemos la grandiosa frase de Jesús: "Perdónalo Señor que no sabe lo que dice".

El Despertar Arocheno también será testigo de una ácida correspondencia de artículos que el dirigente socialista Antonio Domínguez Mozo "Antoñino" mantuvo con José Campos. Antońino en el tercer número escribe contra el alcalde José Campos y

32 "Las Lameras, Juana-lanca, Sierra Pelada, las Solanas, Corte del Pior conocida hoy por la Torre, Corte Noble, Cabeza de Ramos, Valdesortellas, Tinaja Umbrizo, Majadilla, El Brueco, El Bosque junto al Álamo, Los Agudos, las Peńas y la Helechosa, así como la dehesa de Valdeloro, perteneciente a la exGrandeza de España Llanos de la Belleza, comprendida en el número 10 de la Base $5^{\text {a }}$ de la novísima ley de 15 de septiembre última El Álamo, El Galido y el Vínculo dedicadas a cotos de caza.

33 Actas Capitulares 1926-1938. Legajo 30. Archivo Municipal de Aroche.

34 Carolina DÍAZ. "Y la rubia no quería”. Despertar Arocheno. 1 de Junio de 1930. №24. 
su gestión al frente del Ayuntamiento pidiendo una auditoría pública y acusándolo de prevaricación. José campos le responde con una crítica por su condición de empleado de La Comunal. El 15 de junio de 1930 aparece en el Despertar Arocheno un artículo de Antoñino titulado "No ofende el que quiere" contestando a un artículo anterior de Campos "En defensa propia". Antoñino le acusa de cobrar arbitrariamente 1944,83 pesetas del 3\% de cobranza del Impuesto de Utilidades, correspondiente al ejercicio de 1925-26, cantidad que tuvo que devolver para no verse envuelto en un proceso judicial. Le acusa además de cobrar 3578,83 pesetas en recompensa de los gastos que requiere el cargo de Alcalde y de llevarse el tanto por ciento de cobranza del Impuesto de Utilidades de los años 1926 en adelante, no obstante estar encargado de la cobranza un empleado de Secretaría que tenía por este concepto el sueldo anual de 2250 ptas $^{35}$.

El Editorial del periódico del 13 agosto de 1930 se dedicó a publicar un acuerdo del pleno municipal en el que se declaraba la ilegalidad de la cobranza de estas cantidades por el exalcalde José Campos ${ }^{36}$.

Además “Antoñino" acusa a José Campos en el mismo número del Despertar Arocheno de beneficiar a sus parientes en relación a la obtención de lotes en el bien comunal, dice el dirigente socialista:

“¿Es gobernar perjudicar al pueblo en 30.000 pesetas anuales como ocurre con el arriendo de "La Contienda" para beneficiar a parientes, según dice nuestro compañero Sancha en "El Fraternal" (otro periódico) que tienen hoy tres lotes por tres mil pesetas, cuando en el arriendo anterior uno solo le costaba más de 4000?” Antoñino sigue describiendo ejemplos y además dice: “¿Creen que el pueblo ha podido olvidar aquella etapa luctuosa e inquisitorial recordada en horror todavía?"37.

Otro artículo en el Despertar Arocheno nos da muestra de otras más denuncias. Sebastián Carlos Vázquez escribe "como son las chozas son los mesegueros" 38 en el que expone que el contribuyente arocheno está pagando siempre

"por tener sus chicas propiedades grabadas en sus totales rendimientos y en cambio los hacendados forasteros, terratenientes, pagan las cantidades que una junta repartidora le impone en concepto a las utilidades liquidas que se le suponen a sus rentas y propiedades. ¿Y si estos señores tuvieran que pagar con arreglo al valor de sus propiedades y no por el líquido imponible?”.

35 Antonio DOMÍNGUEZ MOZO. "No ofende el que quiere”. Despertar arocheno. No5. 15 de junio de 1930.

36 Editorial. “Para los Excmos Sres Gobernador civil y Delegado de Hacienda de la provincia”. Despertar arocheno. No10. 13 agosto de 1930.

37 Empleados lanzados violentamente de sus puestos por capricho del Dictador, concejales conducidos por las calles como vulgares malhechores por no seguir su política de represalias y despilfarro, farmacéuticos (Se refiere al republicano y miembro de la logia "hijos de la luz": Miguel Lobo Carquesa) expedientados sin motivo, amenazados de encarcelamiento, arrojar de su puesto a veterinarios, figuras representativas de la honradez con sesenta y cinco ańos de servicio y cerda de la centuria de edad, no por mejorar los servicios, sino porque tenían apellidos de quienes no comulgaban con sus procedimiento”... “ así gobernaría un Nerón o un Calígula”.

38 Sebastián CARLOS VÁZQUEZ, “Como son las chozas son los mesegueros”. Despertar Arocheno. No10. 13 agosto de 1930. 
Una vez se proclama la II República el Despertar Arocheno pasó a ser según su propia autodenominación "órgano de la coalición republicano-socialista” y a tener como director a Antonio Domínguez Mozo.

El Editorial del Despertar Arocheno ${ }^{39}$ el 15 de julio de 1931 enaltecía el triunfo en Aroche de la Conjunción Republicano Socialista,

“y este triunfo es la demostración palpable de la equivocación en que vivían los antiguos políticos al creer, engañándose así mismo (como el Sr. Borbon) que la opinión estaba con ellos”... “ya no existen castas, sino ciudadanos de la República, representantes que no están divorciados de su pueblo, porque no han comprado su conciencia”.

El despertar arocheno se convirtió en instrumento de las ideas socialistas y escaparate de promoción de ideas siempre alejadas de la derecha. Un artículo de Vicente Vázquez ${ }^{40}$ en la sección Del ambiente Ideal titulado "No vamos, nos llevan..." describía la inevitabilidad del cambio y de la revolución proletaria.

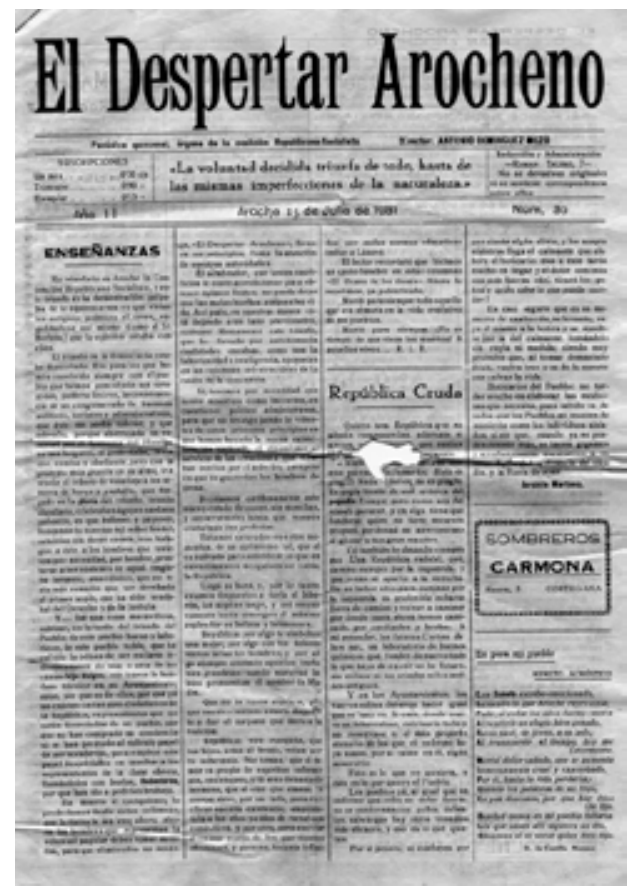

“Cómo podríamos negar el hecho ciertísimo de que la actual situación económica tiene preocupado al capitalismo que de día en día ve obscurecerse más y más el horizonte de su porvenir? Basta ver como de una manera solapada y so pretexto de mantener el orden organiza el elemento que habrá de servirle de fuerza ciega e inconsciente como arma de combate para contener la revolución, protegiendo así su lenta caída ya que no puede evitar las justas reivindicaciones proletarias, mientras acomoda sus leyes a las necesidades 
del tiempo"... "Sería irracional aceptar un estado regresivo del hombre a los trogloditas y sería absurdo dudar que avanzamos hacia un mundo de realidades ideológicas de las que solo somos débiles precursores".

En un artículo de Eugenio Igualada ${ }^{41}$ titulado "Comunismo y Socialismo. Su disparidad y Semejanza" podemos apreciar el interés por la difusión de las ideas socialistas:

"El socialismo difundido y alentado por nuestro maestro Pablo Iglesias, ha conseguido educarnos en colectividad y unificar las aspiraciones del pueblo, hasta conseguir importantes mejoras sociales, hasta el extremo de haber advenido una república que en nuestras manos está el que sea democrática, en un país que como España es indolente, tradicionalista y refractario a la sociabilización, por su manifiesto individualismo, y nada dice mejor en su favor que los hechos demasiados elocuentes y que dan paso a una era de prosperidad para nuestra Patria y para la humanidad, ya que los pueblos viven tangiblemente influenciados por su relación objetiva y subjetiva”.

A partir de julio de 1931 no disponemos de más ejemplares del despertar arocheno. Sin embargo existen otras fuentes a partir de la cuales conocer el contexto del momento y asuntos de especial relevancia. Uno de ellos es la relación habida entre José Campos (quien fuera alcalde de Aroche y capataz de la finca de Román Talero) y Román Talero, dueño de la fábrica de electricidad Santa Teresa. "La comunal" fábrica de harinas y electricidad tendrá como competencia directa a Santa Teresa. Harina y electricidad, serán caballo de batalla entre ambas.

El legajo de Correspondencia (1920-1931) ${ }^{42}$ del archivo municipal de Aroche nos ofrece una nutrida información sobre el asunto Santa Teresa. El 13 marzo de 1931 el gobernador escribe al ayuntamiento de Aroche comunicando Real Orden del Ministerio de Economía por la cual no se permite aplicar sanciones contra Santa Teresa por vender harinas a precios inferiores a los fijados mensualmente por la Sección de Economía. Las instancias estatales no dejaron que el ayuntamiento arocheno aplicara sanciones en contra de Santa Teresa por competencia ilícita. El 21 de agosto el ayuntamiento había escrito un oficio a Santa Teresa al que ésta contesta en 24 agosto de 1931 diciendo que vende la harina al precio que le obligan las circunstancias procurando no rebasar el límite máximo. "Por tales circunstancias hace mucho tiempo que vendemos nuestra marca panadera a precio inferior al de tasa”.

El de 4 septiembre de 1931 la correspondencia estuvo dedicada al asunto de electricidad. Santa Teresa escribe al Ayuntamiento de Aroche porque había declarado lesivo para el municipio el acuerdo tomado por el Ayuntamiento en la sesión extraordinaria del 5 de Febrero del ańo 1928, referente a la prórroga del contrato de suministro de alumbrado público con Santa Teresa. El ayuntamiento quería poner fin al contrato de suministro eléctrico que el capataz de Román Talero y alcalde, José Campos había firmado con el mismo. Se pretendía que fuera "La Comunal", la fábrica de todos, la que ofreciera el servicio de alumbrado público.

41 Eugenio IGUALADA. “Comunismo y Socialismo. Su disparidad y Semejanza”. Despertar Arocheno. n³0. 15 de Julio de 1931.

42 “Entrada y Salida de Correspondencia 1920-1934”. Lejago 122. Archivo Municipal de Aroche. 
El 15 de septiembre de 1931 el Sindicato Agrícola de Aroche escribe al Ayuntamiento para denunciar de nuevo competencia ilícita por parte de Santa Teresa.

La fábrica de harinas "la Comunal" realizó una nueva inversión para la fábrica de electricidad a partir de los rendimientos producidos en la Contienda, pero los enormes gastos derivados a causa de la puesta en marcha y constantes reparaciones de los motores de gasoil les obligaron a endurecer su posición frente a la competidora Santa Teresa ubicada en El Repilado (Jabujo). Como decíamos anteriormente harina y electricidad fueron dos temas de disputa entre el ayuntamiento y el terrateniente Román Talero.

En estos años la movilización política municipal es generalizada, el 26 octubre de $1931^{43}$ se realiza un atestado de la guardia civil en el que se dice que 100 obreros se habían dirigido hacia la Dehesa del Âlamo con el fin de levantar por medio de coacción a los obreros que en dicha finca trabajan. Se dispuso que la guardia civil diera auxilio a los guardas de la finca para proteger la propiedad y la "libertad" de trabajo. Los hechos no se circunscribieron a este caso se extendieron también a otras fincas como Los Lobos, Los Benitos, Monte Blanco, la Zafra, Carretero, Zafia y la Corteganesa. Los obreros decían que su objetivo no era alterar el orden ni causar perjuicios. Las razones esgrimidas por éstos eran que "el patrono de este término", Enrique Ternero, aprovechando la miseria del pueblo pagaba menos de lo acordado entre patronos y obreros. Los trabajadores de la finca decían que ganaban 16 reales cuando lo pactado eran 18 reales, declaraban además que los obreros no los coaccionaron para dejar el trabajo pues ellos voluntariamente habían dejado de trabajar. En 1931 se produce también un incendio en la finca del Álamo propiedad de Enrique Ternero el cual solicitó a instancias políticas mediante correspondencia se practicaran diligencias para averiguar quiénes eran los autores ${ }^{44}$.

Nos gustaría resaltar además la movilización femenina, las mujeres no quedaron apartadas de la agitación política del momento. El alcalde del pueblo de Aroche comunicaba en 1932 al gobernador civil que en dicho pueblo se alteró el orden a consecuencia de una manifestación pública, integrada en su mayoría por mujeres, que invadió el ayuntamiento, pidiendo la destitución del mismo ${ }^{45}$.

Junto a ello, en 1932 varios carabineros habrían sido agredidos por la pretensión del pueblo de Aroche de liberar a 4 contrabandistas de café. El vecindario se amotinó y amenazó a los carabineros con palos y navajas; según la prensa "la llegada de refuerzos apaciguó el incidente" 46 .

En $1933^{47}$ se produjo una huelga general de campesinos en Aroche. Se había celebrado una nueva reunión de la comisión mixta de obreros y patronos, aquellos insistieron en que se les asegurase el trabajo durante un ańo negándose los patronos a toda preten-

43 Diligencia 45 de 1931. Juicios Verbales de Falta. Archivo Municipal de Aroche.

44 "Entrada y Salida de Correspondencia 1920-1934". Lejago 122. Archivo Municipal de Aroche.

45 "El Siglo Futuro" Diario Católico Tradicionalista año 1932.

46 Febus. "Carabineros agredidos". El Sol. 20 de enero de 1932; s.a. "Carabineros Agredidos en Huelva". La Época. 20 de Enero de 1932; s.a. "Intentan linchar a unos carabineros por deterner a cuatro contrabandistas" La Voz; s.a. "Es apedreado el cuartel de carabineros de Aroche" La libertad. 19 de Enero de 1932; s.a. "Pretenden asaltar un cuartel". La Correspondencia Militar. Martes 19 de Enero de 1932.

47 s.a. La época. Telegramas y noticias de la Tarde. 18 mayo de 1933. s.a. La voz. 18 mayo de 1833. 
sión que se apartara de las faenas de siega y recolección. Ante la negativa se declaró la huelga general provocándose una situación grave pues la cosecha estaba madura y podía perderse.

Acontecimientos como éstos se sucedieron hasta que se produjo el golpe de estado. Tanto el proyecto de La Comunal, fábrica de electricidad y harinas, y otras tantas cuestiones se vieron afectadas por el pronunciamiento militar que terminó en guerra civil.

\section{Conclusiones}

A través del periódico "El Despertar Arocheno" y los acontecimientos locales trabajados en el archivo histórico municipal hemos señalado algunos de los acontecimientos sucedidos en estos años de movilización política. En el caso descrito hemos reconocido que algunos vecinos vivían completamente alejados del espacio público y la política. Quizás, aquellos labradores centrados en sus tierras y labores e "intelectuales", serían los más identificables. En el caso de Aroche, son los jornaleros y significativamente la Sociedad de obreros el Alba la que organizó y en torno a la cual se gestó la movilización política. No podemos olvidar la influencia de las ideas republicanas en los líderes locales y los apoyos, vínculos e impulsos que las mismas a través de personajes como Miguel Lobo Carquesa, farmaceútico de la villa, ofrecieron al impulsor de la Sociedad de Obreros Félix Lúnar. El Despertar Arocheno es ante todo una demostración de la actividad política local. "Los caballeros de la tierra" y "los enemigos del sol" serían la antítesis a otra parte de la población concienciada, movilizada y deseosa de intervenir y gestionar la res pública. 